mammals, and salivary glands of mammals, insects and molluscs. For good measure there are also at least mentions of the adrenal cortex, the thyroid and the parathyroid. All this is within the compass of a mere 250 pages, achieved not by omission but by virtue of the author's enviably direct style.

The approach wherever possible is quantitative and starts from the premise that things may not be nearly so complicated as they might seem at first sight. "It would be easy to dwell on the great diversity of electrophysiological patterns observed in different gland cells, but it may be more profitable to point out the many similarities" is how the last, integrative, chapter begins. It is one of the few asides the author permits himself, and it conveys the spirit which informs most of the preceding text: above all, no mystification.

In so far as electrophysiology in its strict sense is concerned, the author's message is the following. In cells which are not "excitable", mainly vertebrate and insect exocrine cells, changes in membrane potential are contingent on, rather than necessary to secretion. For the experimentalist they serve the useful purpose of signalling the increase in ionic conductance which is essential to load the cell through the basal membrane. Recent investigations, particularly those of the author and his colleague Iwatsuki, have provided strong support for the idea that the
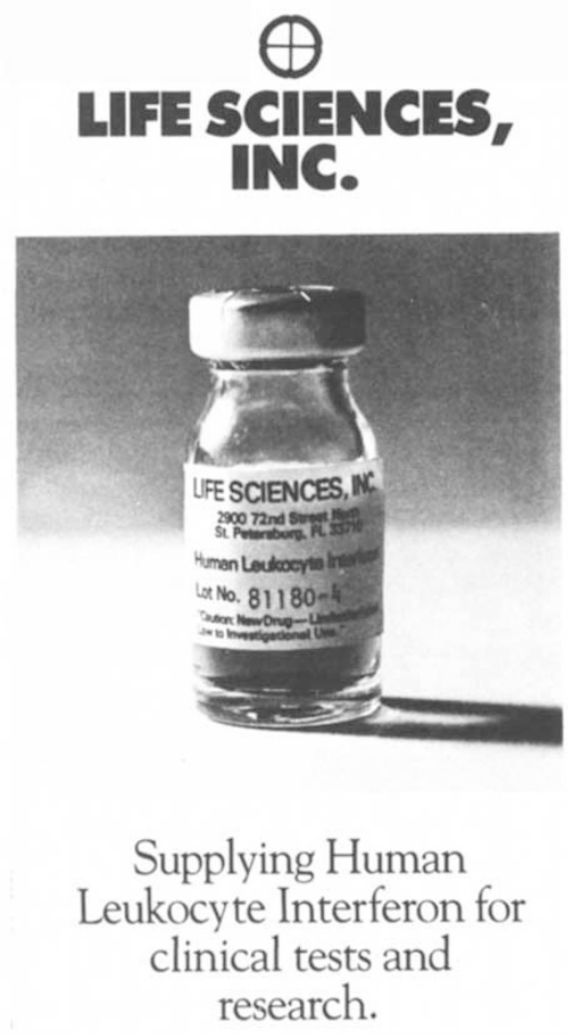

2900-72nd Street North

St. Petersburg, Florida 33710 (813) 345-9371

Circle No.04 on Reader Enquiry Card. conductance changes brought about by secretagogues are secondary to an increase in cytosolic calcium. On the other hand, in vertebrate endocrine cells and some molluscan exocrine cells, which are excitable, action potentials may perform an essential role in opening voltagesensitive ion channels, particularly to calcium. The evidence bearing on these hypotheses is assembled with great economy, missing links are underlined and for the faint-hearted each of the 14 chapters has a short, lucid summary.

The electrophysiology of secretion is deemed to have been discovered in 1857 by de Bois Reymond. Since then, until recently, progress was unremarkable. Schäfer's textbook of physiology of 1898 devotes about a page to the subject, pride of place being given to the work of Bayliss and Bradford on the salivary gland. More than 50 years later in the eleventh edition of Starling's textbook of physiology the subject rates only a short paragraph and the same papers are cited. Ten years later the thirteenth edition has no trace of the subject. If this monograph does not persuade teachers of physiology to pay some attention to current work on secretion, nothing will. For those who work in the field, it need hardly be said that the book is indispensable.

B.L. Ginsborg is a Professor in the Department of Pharmacology at the University of Edinburgh.

\title{
The questions of what and where to eat
}

\section{N.B. Davies}

\section{Foraging Behavior: Ecological, Ethological and Psychological Approaches. Edited by Alan C. Kamil and Theodore D. Sargent. Pp.534. ISBN 0-8240-7068-2. (Garland STPM Press: 1981.) $\$ 52.50$.}

ALl predators, whether lions chasing gazelle on the African plains or birds looking for berries in a back garden, must make decisions - where to hunt, which prey to select, when to move on to a new feeding area and so on. Ethologists have been interested in the costs and benefits associated with these decisions and how they influence survival and reproductive success, while psychologists have been more concerned with the mechanisms that underlie the behaviour, for example motivational and learning rules. Based on an Animal Behaviour Society meeting in Seattle, Washington, this collection of essays is a stimulating summary of the recent advances in these approaches.

The book is divided into four sections, each with an introduction by the editors. The first considers optimal foraging theory which is an attempt to predict which particular trade-off between costs and benefits will give the maximum net benefit to the individual. Krebs, Houston and Charnov give a good review of the models and show the generality of simple decision rules. Subsequent chapters show that the same model can be used to predict how long a bee (Pyke, Waddington, Heinrich) or hummingbird (Gass, Montgomerie) should remain at a flower before moving on to the next one, how many prey a parent bird should carry back to the nest (Orians) and for how long a male dungfly should copulate, because all of these decisions involve the exploitation of a depleting resource.

In the second section, several field studies emphasize the complexity of foraging behaviour in nature. For example, it is clear that predictions based solely on energy maximization do not describe prey choice in protozoa (Rapport), wading birds (Goss-Custard) or monkeys (Glander) because all need a critical balance of nutrients in their diet. Another complication, shown clearly in the chapter on sanderling territories by Myers, Connors and Pitelka, is that decision rules may be determined by long-term advantage rather than immediate gain.

Predators presumably do not work out mathematical equations to decide how to forage, and Section 3 examines some of the simple rules they may use to achieve the optimal behaviour. Pulliam shows that a learning rule, known as the "matching law", derived from psychological experiments, makes good functional sense as it maximizes the rate of food intake. Pietrewicz and Kamil describe some elegant experiments on how birds recognize moths and relate their findings to the evolution of crypsis by the prey (Sargent). The final section on the genetic basis of foraging behaviour includes an excellent chapter by Arnold on prey recognition by garter snakes.

Several authors, Zach and Smith, for example, suggest that nature is much too complex for simple models to be of any use. This seems an unnecessarily pessimistic point of view. Not only does the rejection of simple models often lead to a better understanding of behaviour, but it is also possible that what looks like very complicated behaviour will after all turn out to involve simple decisions once the field worker has understood properly the natural history of his animal and its environment.

N.B. Davies is Demonstrator in Zoology at the University of Cambridge and a Fellow of Pembroke College. 